\title{
Behavior Research Methods, Instruments, \& Computers Articles In Press
}

The following is a list of forthcoming Behavior Research Methods, Instruments, \& Computers articles that are currently in press. They are given in approximate order of acceptance. Each entry. includes the name and address of the author with whom to communicate for further prepublication information.

"Input protection for the laboratory computer" by S.A. Hertel \& S.E. Edgell (S.E.E., Dept. of Psychology, Univ. of Louisville, Louisville, KY 40292)

"Tachistoscopic display using color look-up table display devices" by P. Dixon (P.D., Dept. of Psychology, Univ. of Alberta, Edmonton, AB T6G 2E9, Canada)

“FISH: A commons dilemma simulation" by R. Gifford \& J. Wells (R.G., Dept. of Psychology, Univ. of Victoria, PO Box 3050, Victoria, BC V8W 3P5, Canada)

“Equivalence of two manufacturers' precision food pellets for rats" by W.M. Baum (W.M.B., Dept. of Psychology, Univ. of New Hampshire, Durham, NH 03824-3567)

"Measuring recognition performance using computer-based and paper-based methods"' by P.-A. Federico (P.-A.F., Code 15, Navy Personnel R\&D Ctr. (NPRDC), San Diego, CA 92152-6800)

"The Observer: A software system for collection and analysis of observational data" by L.P.J. Noldus (L.P.J.N., Noldus Info. Technology b.v., Univ. Business \& Tech. Ctr., Vadaring 51, NL-6702 EA Wageningen, The Netherlands)

“A Macintosh II psychophysiology system” by T.C. Bates (T.C.B., Dept. of Psychology, Univ. of Auckland, Private Bag, Auckland, New Zealand)

"An automated positive reward method for measuring acoustic sensitivity in fish" by H.Y. Yan \& A.N. Popper
(H.Y.Y., Dept. of Zoology, Univ. of Maryland, College Park, MD 20742)

"Psychmuse: A Macintosh system for psychomusicology research" by M. Boltz, M. Kapadia \& R. Joyner (M.B., Dept. of Psychology, Haverford College, Haverford, PA 19041)

"A FORTRAN 77 program for sample size determination in replication attempts when effect size is uncertain" by R. Gillett (R.G., Dept. of Psychology, Univ. of Leicester, Leicester LE1 7RH, U.K.)

"A method for utilizing a single port for multiple functions on the IBM PC or compatible system" by K.R. Zurn, T.A. Tatham \& T. Repstad (K.R.Z., MED Associates, Inc. Box 47, East Fairfield, VT 05448)

"A behavioral frequency discrimination paradigm for use in adult primates" by G.H. Recanzone, W.M. Jenkins, G.T. Hradek, \& M.M. Merzenich (G.H.R., HSE 871, Box 0732, Univ. of California, San Francisco, CA 94143-0732)

"Independent control of dual video subsystems on IBM-PC compatibles"' by K.J. Hawley (K.J.H., Dept. of Psychology, Univ. of Utah, Salt Lake City, UT 84112)

"Console-protocol and Turbo-C options for the McClelland \& Rumelhart PDP-Handbook programs"' by P.L. Emerson (P.L.E., Dept. Psychol., Cleveland State Univ., Cleveland, $\mathrm{OH}$ 44118) 